\title{
High efficiency phosphorescent organic light emitting diodes using triplet quantum well structure
}

\author{
Sung Hyun Kim and Jyongsik Jang \\ School of Chemical and Biological Engineering, Seoul National University, Shinlim-dong, Kwanak-gu, \\ Seoul 151-742, Korea \\ Jae-Min Hong \\ Opto Electronic Materials Research Center, Korea Institute of Science and Technology, P.O. Box 131, \\ Cheongryang, Seoul 130-650 Korea \\ Jun Yeob Lee ${ }^{\text {a) }}$ \\ Department of Polymer Science and Engineering, Dankook University, Hannam-dong, Yongsan-gu, Seoul \\ 140-714, Korea
}

(Received 11 January 2007; accepted 24 March 2007; published online 23 April 2007)

\begin{abstract}
Light emission in phosphorescent quantum well structure which can confine excitons within an emitting layer was investigated. A multilayer quantum well structure which has a narrow triplet band gap host material sandwiched between wide triplet band gap host materials was designed, and device performances were studied. The multilayer emitting structure gave high efficiency of $47 \mathrm{~cd} / \mathrm{A}$ compared with $11 \mathrm{~cd} / \mathrm{A}$ of standard green devices. (C) 2007 American Institute of Physics. [DOI: $10.1063 / 1.2731435$ ]
\end{abstract}

Light emission in phosphorescent organic light emitting diodes (PHOLEDs) depends on the properties of the organic material in the devices. ${ }^{1-4}$ In particular, the energy level of the organic material has a great influence on the light emission in PHOLEDs. Depending on the energy level of charge transport materials, host, and dopant, different mechanisms dominate the light emission and recombination in PHOLEDs. Charge trapping and energy transfer mechanisms have been known to be a light emission path for the host and dopant system. Charge trapping plays a main role in red and green PHOLEDs, and energy transfer is the major light emission path for blue PHOLEDs. ${ }^{5}$ In addition, the performances of PHOLEDs are greatly affected by the charge transport and charge recombination in the light emitting layer (EML). ${ }^{6-10}$.

The most efficient way to get high recombination efficiency in PHOLEDs is to balance holes and electrons in the emitting layer. ${ }^{6,8,9,11-14}$ It was reported by $\mathrm{He}$ et al. that the efficiency of green PHOLEDs could be doubled using a double layer emitting structure. ${ }^{6}$ The use of an effective hole or exciton blocking layer could also enhance the recombination efficiency of PHOLEDs. ${ }^{8,11}$ Other than these, host and dopant materials were found to have a great impact on the recombination efficiency of PHOLEDs. ${ }^{9,12-14}$

Another way to get high efficiency in OLED is to confine excitons inside an emitting layer using a multilayer quantum well structure. ${ }^{15,16}$ There have been several reports about quantum well structure which can confine holes or excitons within an emitting layer. Qiu et al. improved quantum efficiency of tris(8-hydroxyquinoline) aluminium ( $\left.\mathrm{Alq}_{3}\right)$ devices by $120 \%$ using a copper phthalocyanine/ $N, N^{\prime}$-di(1-naphthyl)- $N, N^{\prime}$-diphenylbenzidine (NPB) quantum well structure. ${ }^{15}$ They also reported an $\mathrm{Alq}_{3} /$ rubrene quautum well structure and exciton confinement in rubrene layer. ${ }^{16}$ There was four times improvement of quantum efficiency using rubrene as a quantum well. However, there was

\footnotetext{
a) Author to whom correspondence should be addressed; FAX:82-2-709-
} 2614; electronic mail: leej17@dankook.ac.kr no report about triplet quantum well structure with phosphorescent dopants in EML.

In this work, a phosphorescent quantum well structure which can confine charges and excitons inside EML was developed to improve the efficiency of green PHOLEDs, and the performances of green PHOLEDs were correlated with the device structure.

Device configurations used in this experiment were indium tin oxide $(150 \mathrm{~nm}) / N, N^{\prime}$-diphenyl$N, N^{\prime}$-bis-[4-(phenyl- $m$-tolyl-amino)-phenyl]-biphenyl-4, $4^{\prime}$ diamine $(60 \mathrm{~nm}) / \mathrm{NPB}(30 \mathrm{~nm}) / \mathrm{EML}(30 \mathrm{~nm}) / \mathrm{biphenoxy}-\mathrm{bi}(8-$ hydroxy-3-methylquinoline) aluminum (Balq) $(5 \mathrm{~nm}) / \mathrm{Alq}_{3}$ $(25 \mathrm{~nm}) / \mathrm{LiF}(1 \mathrm{~nm}) / \mathrm{Al}(200 \mathrm{~nm})$. Four devices were fabricated to investigate the effect of quantum well structure on device performances (Fig. 1). Two standard devices with a single EML, one device with three EMLs and one device with five EMLs, were prepared. The total thickness of the EML was constant for all devices. Device I has ( $4,4^{\prime}-N, N^{\prime}$-dicarbazole)biphenyl (CBP) as a host for the EML, and device II has PH1 as a host for the EML. Devices III and IV have PH1 EMLs sandwiched between CBP EMLs.

Light emitting material was a mixture of CBP and tris(2phenylpyridine $)$ iridium $\left(\operatorname{Ir}(\mathrm{ppy})_{3}\right)$ or $\mathrm{PH} 1$ and $\operatorname{Ir}(\mathrm{ppy})_{3}$. $\mathrm{PH} 1$ was supplied from Merck Co., and it has a spirobifluorenetype backbone structure with high electron transport properties. Triplet band gap of PH1 was $2.4 \mathrm{eV}$ and the highest occupied molecular orbital and the lowest unoccupied molecular orbital were 5.9 and $2.8 \mathrm{eV}$. Balq was a hole blocking material and the electron transport material was $\mathrm{Alq}_{3}$. The $\mathrm{LiF} / \mathrm{Al}$ double layer was used as a cathode system. Organic materials were deposited at a base pressure of $5 \times 10^{-7}$ Torr at a deposition rate of $1 \AA / \mathrm{s}$, and $\mathrm{Al}$ was evaporated at a rate of $2 \AA / s$. Current density-voltageluminance characteristics of the devices were measured with Keithley 2400 and PR 650 spectrophotometer, and the energy level of the material was measured by surface analyzer (Riken-Keiki AC2) and ultraviolet/visible absorption spectroscopy. 


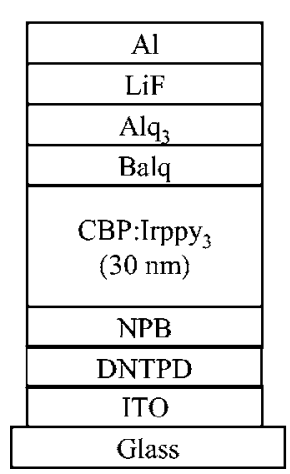

Device I

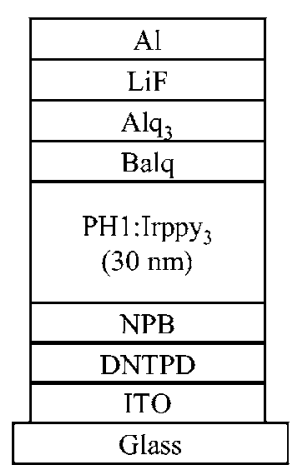

Device II

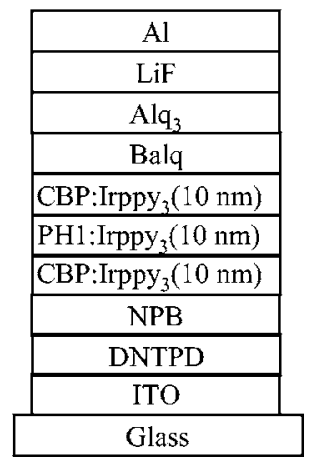

Device III

\begin{tabular}{|c|}
\hline $\mathrm{Al}$ \\
\hline $\mathrm{LiF}$ \\
\hline $\mathrm{Alq}_{3}$ \\
\hline Balq \\
\hline CBP:Irppy ${ }_{3}(6 \mathrm{~nm})$ \\
\hline PH1:Irppy ${ }_{3}(6 \mathrm{~nm})$ \\
\hline CBP:Irppy ${ }_{3}(6 \mathrm{~nm})$ \\
\hline PHI:Irppy ${ }_{3}(6 \mathrm{~nm})$ \\
\hline CBP:Irppy ${ }_{3}(6 \mathrm{~nm})$ \\
\hline NPB \\
\hline DNTPD \\
\hline ITO \\
\hline Glass \\
\hline
\end{tabular}

Device IV
FIG. 1. Device configurations of standard and quantum well devices.
One efficient way to get high efficiency in PHOLEDs is to confine charges and excitons in the EML to increase the recombination efficiency of electrons and holes. Even though conventional OLED structures can also give high efficiency through charge balance in the EML, a quantum well structure which can confine excitons in the EML is required to improve the device efficiency further because holes and electrons are not well balanced in common device structures. To get maximum light output through exciton confinement in the device, a phosphorescent quantum well structure was developed.

Current density and luminance of the devices with different EML structures were measured to study the effect of quantum well structure on the charge injection in PHOLEDs. Figure 2 shows the current density and luminance of green devices with different EML structures. Comparing CBP and PH1 devices, the PH1 device showed higher current density
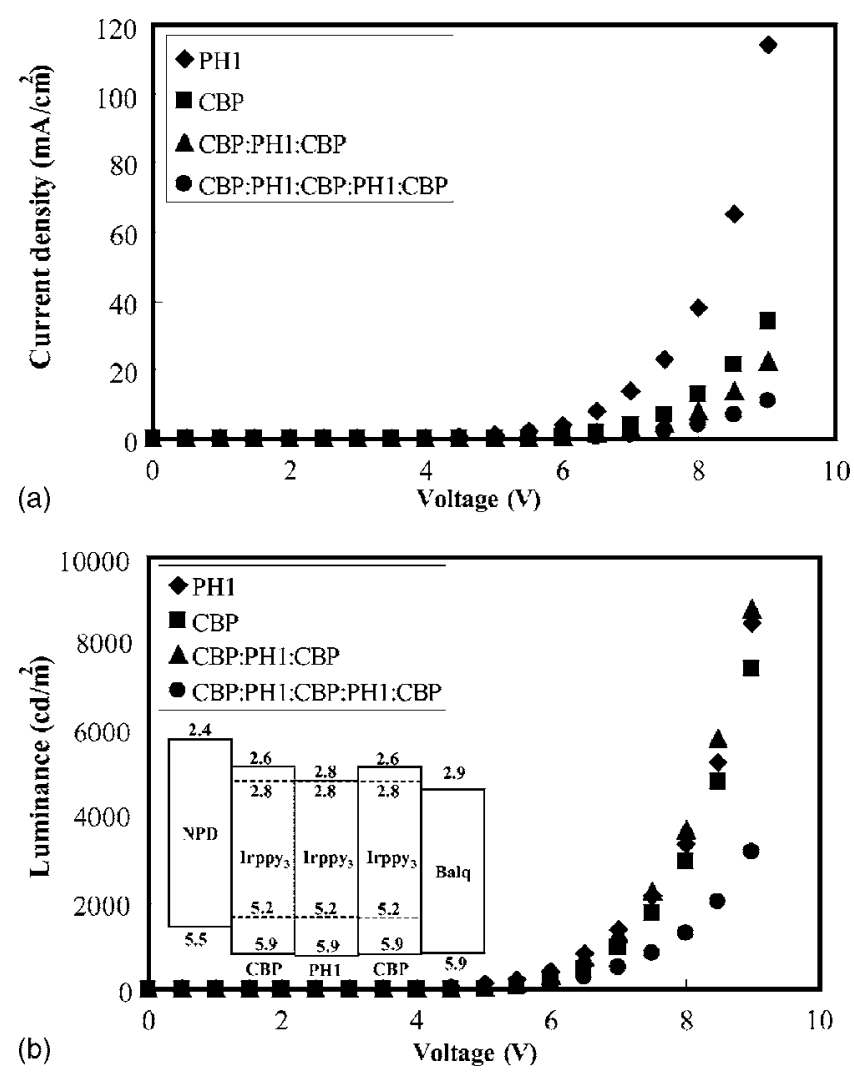

FIG. 2. Current density-voltage-luminance curves of phosphorescent quantum well devices: (a) current density-voltage; (b) luminance-voltage. tum well devices: (a) current density-voltage; (b) luminance-voltage. rescent devices.
Downloaded 23 Nov 2007 to 147.46 .244 .154. Redistribution subject to AlP license or at the same driving voltage than CBP. The high current density in the PH1 device is mostly due to low energy barrier for electron injection from Balq to PH1. The energy barrier for electron injection is $0.1 \mathrm{eV}$ between PH1 $(2.8 \mathrm{eV})$ and Balq $(2.9 \mathrm{eV})$, while it is $0.3 \mathrm{eV}$ between $\mathrm{CBP}(2.6 \mathrm{eV})$ and Balq. As holes are mostly trapped by dopants in CBP: $\operatorname{Ir}(\mathrm{ppy})_{3}$ and PH1: $\operatorname{Ir}(\mathrm{ppy})_{3}$ devices, host materials do not contribute greatly to the hole injection or transport. Therefore, high current density in PH1 devices mostly originates from high electron density in EML. Compared with standard CBP and PH1 devices, devices III and IV with quantum well structures showed lower current densities than standard devices. Devices III and IV have CBP layers at the interface with hole transport layers and electron transport layers, so the current injection from the charge transport layer to EML is similar to CBP devices. However, charges can be trapped inside EML because of the narrow band gap of PH1 compared with CBP, leading to low current densities in quantum well devices. The luminance of multilayer devices showed different tendencies from current density. Device III which has PH1 at the center of EML and CBP at the interface with NPB and Balq showed the same luminance value as the PH1 device in spite of the low current density. The luminance value is usually determined by the degree of recombination of electron and holes, and the high luminance value in device III indicates high recombination efficiency in device III.

To get more detailed information about recombination in quantum well devices, current efficiency of quantum well devices was plotted against luminance in Fig. 3. Quantum well devices showed a current efficiency of $47 \mathrm{~cd} / \mathrm{A}$ compared with $11 \mathrm{~cd} / \mathrm{A}$ of the PH1 standard device and $24 \mathrm{~cd} / \mathrm{A}$

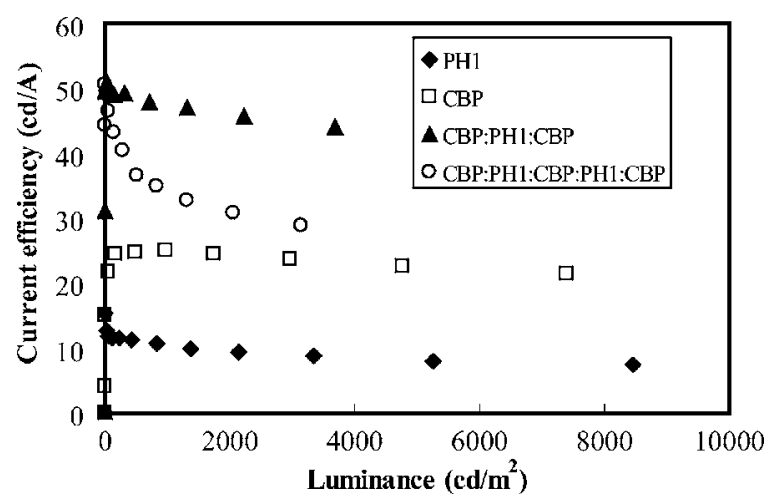

FIG. 3. Efficiency-luminance curves of multilayer quantum well phospho-

to AIP license or copyright; see http://apl.aip.org/apl/copyright.jsp 
of the CBP device. The current efficiency of PH1 could be improved by more than four times by using a CBP layer in the quantum well structure. The high recombination efficiency in device III can be explained by exciton confinement in EML. In general, light emission in PHOLEDs is induced via triplet excitons, and exciton confinement in the EML can give high current efficiency. In device III, triplet excitons can be confined in PH1 because the triplet energy gap of PH1 is $2.4 \mathrm{eV}$ compared with $2.6 \mathrm{eV}$ of CBP. There is an energy barrier of $0.2 \mathrm{eV}$ for triplet excitons, resulting in efficient trapping of triplet excitons in PH1 layer. The CBP layer plays a role of exciton blocking layer which can confine excitons inside the PH1 layer. The other role of the CBP layer is to transport holes from the NPB to the PH1 layer. PH1 has a bifluorene structure which is suitable for electron transport, resulting in hole accumulation at the interface between NPB and PH1. However, CBP has good hole transporting properties due to the carbazole unit and reduces hole accumulation at the NPB-EML interface, shifting the recombination zone from the hole transport layer (HTL) side to the EML side. In addition, electrons can be effectively trapped in the PH1 layer because of the $0.2 \mathrm{eV}$ energy barrier between PH1 and CBP. Therefore, current efficiency value could be greatly increased due to efficient recombination and exciton confinement. The power efficiency of quantum well devices was also enhanced by a factor of 4 because of high current efficiency. The rather low efficiency in device IV compared with that in device III is due to discontinuous film formation in device IV. It was confirmed with an atomic force microscopic analysis of a $6 \mathrm{~nm}$ thick PH1 film, and an island structure was observed. Thin CBP $(6 \mathrm{~nm})$ and PH1 layers can confine excitons inside EML, but discontinuous film formation has some negative effect on efficiency.

Exciton confinement in the quantum well structure also affected the electroluminescent (EL) spectrum of PHOLEDs. EL spectra of quantum well devices are shown in Fig. 4. CBP devices show an emission peak at $511 \mathrm{~nm}$, while PH1 devices show an emission peak at $515 \mathrm{~nm}$. EL spectra were redshifted in PH1 due to small triplet band gap, and EL spectrum of quantum well devices can give a clue about recombination in quantum well devices. Devices III and IV have mixed spectra of PH1 and CBP devices with a peak maximum of $513 \mathrm{~nm}$, implying that emission comes out of both PH1 and CBP layers. Another change of EL spectra in the quantum well structure is the disappearance of emission around $420 \mathrm{~nm}$ which is assigned to NPB emission. NPB emission is clearly observed both in CBP and PH1 devices due to electron overflow from EML to NPB and hole accumulation at the interface. However, the NPB emission was

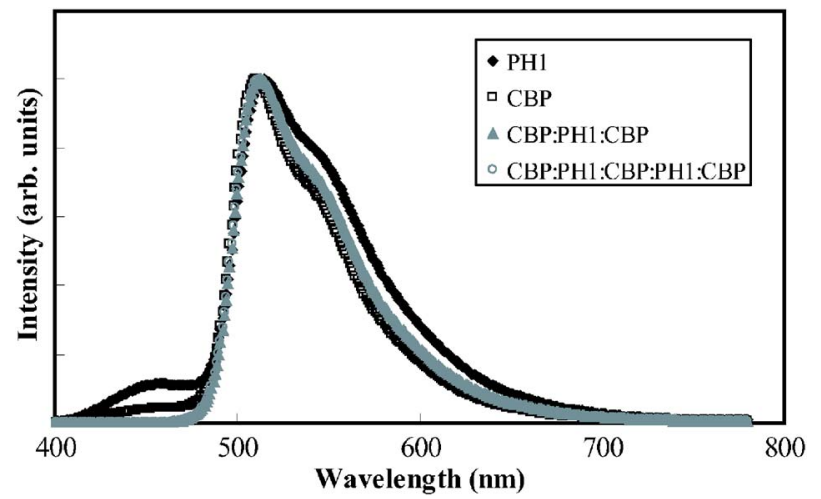

FIG. 4. Electroluminescence spectra of quantum well devices.

not observed in the quantum well device, indicating that electron and hole recombinations mostly occur inside EML.

In conclusion, a multilayer quantum well structure which can confine charges and excitons inside an emission layer enhanced the luminance efficiency of green PHOLEDs by more than four times. Electrons could be trapped inside an emitting layer using a quantum well structure, and triplet excitons could also be confined in EML.

${ }^{1}$ J. Shen and J. Yang, J. Appl. Phys. 83, 7706 (1998).

${ }^{2}$ J. Yang and J. Shen, J. Appl. Phys. 84, 2105 (1998).

${ }^{3}$ T. Mori and T. Mizutani, Polym. Adv. Technol. 8, 471 (1997).

${ }^{4}$ L. I. Liu, N. N. Barashkov, C. P. Palsule, S. Gangopadhyay, and W. L. Borst, J. Appl. Phys. 88, 4860 (2000).

${ }^{5}$ B. D. Chin, M. C. Suh, M. Kim, S. T. Lee, H. D. Kim, and H. K. Chung, Appl. Phys. Lett. 86, 133505 (2005).

${ }^{6} \mathrm{G}$. He, M. Pfeiffer, K. Leo, M. Hofmann, J. Birnstock, R. Pudzich, and J. Salbeck, Appl. Phys. Lett. 85, 3911 (2004).

${ }^{7}$ X. Zhou, D. S. Qin, M. Pfeiffer, J. Blochwitz, A. Werner, J. Crechsel, B. Maennig, K. Leo, M. Bold, P. Erk, and H. Hartmann, Appl. Phys. Lett. 81, 4070 (2002).

${ }^{8}$ M. Ikai, S. Tokito, Y. Sakamoto, T. Suzuki, and Y. Taga, Appl. Phys. Lett. 79, 156 (2001).

${ }^{9}$ H. Inomata, K. Goushi, T. Masuko, T. Konno, T. Imai, H. Sasabe, J. J. Brown, and C. Adachi, Chem. Mater. 16, 1285 (2004).

${ }^{10}$ V. Adamovich, S. R. Cordero, P. I. Djurovich, A. Tamayo, M. E. Thompson, B. Andrade, and S. R. Forrest, Org. Electron. 4, 77 (2003).

${ }^{11}$ K. Okumoto and Y. Shirota, Chem. Mater. 15, 699 (2003).

${ }^{12}$ K. Wong, Y. Chen, Y. Lin, H. Su, and C. Wu, Org. Lett. 7, 5361 (2005).

${ }^{13}$ S. Lamansky, P. I. Djurovich, D. Murphy, F. Abdel-Razzaq, R. Kwong, I. Tsyba, M. Bortz, B. Mui, R. Bau, and M. E. Thompson, Inorg. Chem. 40, 1704 (2001).

${ }^{14}$ S. Lamansky, P. Djurovich, D. Murphy, F. Abdel-Razzaq, H. Lee, C. Adachi, P. E. Burrows, S. R. Forrest, and M. E. Thmopson, J. Am. Chem. Soc. 123, 4304 (2001).

${ }^{15}$ Y. Qiu, Y. Gao, P. Wei, and L. Wang, Appl. Phys. Lett. 80, 2628 (2002).

${ }^{16}$ Y. Qiu, Y. Gao, L. Wang, P. Wei, L. Duan, D. Zhang, and G. Dong, Appl. Phys. Lett. 81, 3540 (2002). 